\title{
Fé e constitucionalismo moderno na independência do Brasil
}

DOI: $10.15175 / 1984-2503-201810303$

\section{Gabriel Lima Marques}

\begin{abstract}
Resumo
Este trabalho tem por objetivo investigar o movimento constitucionalista luso-brasileiro na virada do século XVIII para o XIX, face a possibilidade de apropriação cultural do sebastianismo presente na cultura política e religiosa, a partir dos sermões de religiosos, semanários e periódicos. O sebastianismo assumiu várias versões, sempre atreladas a situações de dificuldades. Por seu turno, o constitucionalismo moderno em Portugal e no Brasil, que supostamente superaria o messianismo sebastianista pode ter sido vivenciado como solução para todas as mazelas políticas e sociais e que se instauraria um tempo de justiça, felicidade e paz, sob o manto da fé católica, instrumento tomado para facilitar a transição do velho para um novo regime.
\end{abstract}

Palavras-chave: Sebastianismo; fé; constitucionalismo.

\section{Fe y constitucionalismo en la independencia de Brasil}

\section{Resumen}

Este trabajo tiene por objeto investigar el movimiento constitucionalista luso-brasileño en la transición del siglo XVIII al XIX con respecto a la posibilidad de apropiación cultural del sebastianismo presente en la cultura política y religiosa, a partir de los sermones de religiosos, semanarios y periódicos. El sebastianismo asumió varias versiones, siempre ligadas a situaciones de dificultades. Por su parte, es posible que el constitucionalismo moderno en Portugal y Brasil, que supuestamente superaría al mesianismo sebastianista, se haya vivido como solución a todas las adversidades políticas y sociales, y que contribuiría a instaurar un tiempo de justicia, felicidad y paz, bajo el manto de la fe católica, instrumento tomado para facilitar la transición del viejo régimen al nuevo.

Palabras clave: sebastianismo; fe; constitucionalismo.

\section{Faith and constitutionalism in Brazilian Independence}

\section{Abstract}

The following work aims to investigate the Luso-Brazilian constitutionalist movement at the turn of the nineteenth century in light of a possible cultural appropriation of Sebastianism present in political and religious culture, based on religious sermons, weekly newspapers, and journals. Sebastianism assumed various forms, with all of these linked to situations of difficulty. Purported to overcome Sebastianist Messianism, modern constitutionalism in Portugal and Brazil, on the other hand, may have been experienced as a solution for all political and social evils, establishing a time of justice, joy, and peace under the mantle of the Catholic Faith, an instrument harnessed to facilitate the transition from the old to a new regime.

Keywords: Sebastianism; faith; constitutionalism.

\footnotetext{
* Professor (40 horas - DE) de Direito Constitucional da Universidade Federal do Amapá - UNIFAP. Advogado. Doutorando em Direito Público na Universidade do Estado do Rio de Janeiro - UERJ. Mestre em Direito pela Universidade Federal do Rio de Janeiro - UFRJ. Pós-Graduado em Direito e Saúde pela Escola Nacional de Saúde Pública Sérgio Arouca - ENSP da Fundação Oswaldo Cruz (FIOCRUZ). Bacharel em Direito pela Universidade do Estado do Rio de Janeiro - UERJ. E-mail: gabriel-marques@hotmail.com. Orcid ID: https://orcid.org/0000-0001-5977-8034
} 


\section{Passagens. Revista Internacional de História Política e Cultura Jurídica}

Rio de Janeiro: vol. 10, n⿳30 , setembro-dezembro, 2018, p. 399-413.

\section{Foi et constitutionnalisme lors de l'Indépendance du Brésil \\ Résumé}

Cet article a pour objectif d'analyser, en se basant sur des sermons de religieux, des revues hebdomadaires et autres périodiques, le mouvement constitutionnaliste luso-brésilien du tournant du XIX siècle face à la possibilité d'appropriation culturelle du sébastianisme présent dans la culture politique et religieuse. Le sébastianisme a connu différentes phases toujours liées à des situations difficiles. De son côté, le constitutionnalisme moderne du Portugal et du Brésil, dont on pensait qu'il permettrait de dépasser le messianisme sébastianiste, a souvent été considéré comme une solution à tous les problèmes politiques et sociaux permettant d'instaurer une époque de justice, de bonheur et de paix sous l'égide de la foi catholique, qui a elle servi d'instrument pour faciliter la transition entre un ancien et un nouveau régime.

Mots-clés : sébastianisme ; foi ; constitutionalisme.

\section{巴西独立运动中的宗教信仰和宪政主义 \\ 摘要}

本文目的是研究十八世纪末和十九世纪初巴西一葡萄牙的宪政主义运动, 及其通过宗教布道, 研讨会, 出版的 刊物, 对赛巴斯提安主义的吸收一赛巴斯提安主义对匍萄牙政治文化与宗教有着广泛的影响。赛巴斯提安主义 有多重含义, 但是它总是在遇见困境时出现。巴西和葡萄牙的宪政主义运动借助了赛巴斯提安主义的救世主思 想，认可民间笃信的赛巴斯提安王返回葡萄牙并拯救葡萄牙人民于水火之中，在其国土上建立一个公正，幸 福, 和平的乐土。宪政主义运动借助了葡萄牙固有的宗教信仰, 从而使得旧制度转变为新制度的交替过程更加 平缓和容易。

关键词：赛巴斯提安主义，宗教信仰，宪政主义。

\section{Introdução}

É já fato há um bom tempo para historiografia brasileira que no movimento político da independência do Brasil houve uma intensa participação do clero católico. Levantamentos dão conta de que quando das cortes de Lisboa - onde alimentada ainda a utopia do poderoso império luso-brasílico - 26 padres foram escolhidos para representar os interesses das províncias brasileiras junto a metrópole. Já em outro momento - mais precisamente quando desfeito aquele sonho e convocada logo a seguir a primeira constituinte - de um total de 100 deputados, 22 eram sacerdotes (BRASIL, 1978, p. 12). ${ }^{a}$

Tal volume se explica, pois como em Portugal e por consequência em seu maior território - o Brasil - as ideias típicas do Século das Luzes conviveram mitigadas pela valorização da religião como a forma mais elevada do conhecimento (NEVES, 2003, p. 27). ${ }^{a}$ Coube, portanto, à instrumentalização da fé cristã, entre a Revolução do Porto de 1820 e a outorga da carta política de 1824 - período que retém a atenção do presente trabalho - 0 papel de transmitir as novidades liberais. 


\title{
Passagens. Revista Internacional de História Política e Cultura Jurídica
}

Rio de Janeiro: vol. 10, n⿳30, setembro-dezembro, 2018, p. 399-413.

Assim sendo, palavras como "Constituição" - o que poucos no Brasil estavam acostumados a lidar em sentido - era tanto a ordem do dia em inúmeros sermões de religiosos, tal qual o proferido em 1821 por um Cônego da Capela Real no Rio de Janeiro, conforme se vê no trecho a seguir:

\begin{abstract}
Constituição, senhores, é o baluarte da inocência, o prêmio do merecimento, a hipoteca da segurança pública, o fiador da propriedade individual, o sacrário da bem entendida liberdade, o refúgio dos miseráveis, o brasão do sábio, o pergaminho da verdadeira nobreza da nação. Constituição é a defesa do Estado, o apoio do trono, a escala da grandeza, a melhor herança do povo, o nível da perfeita igualdade cívica. Constituição é o código universal da sociedade, a regra infalível da justiça, o Evangelho político da Nação, o compêndio de todas as obrigações, o manual cotidiano do cidadão (NEVES, 2003, p. 151). ${ }^{\mathrm{b}}$
\end{abstract}

Quanto era igualmente assunto central em inúmeros periódicos e folhetos que ilustravam as concepções de seus redatores - religiosos ou não - a partir da arraigada catolicidade popular. Caso da paródia intitulada "Padre Nosso Constitucional", que dispunha:

Constituição portuguesa, que estás em nossos corações, santificado seja o teu nome, venha a nós o teu regime constitucional, seja feita sempre a tua vontade, um melhoramento de agricultura, navegação e comércio nos dá hoje e cada dia; perdoa-nos os defeitos e crimes passados, assim como nós perdoamos aos nossos devedores, que não nos podem pagar, não nos deixes cair em tentação dos velhos abusos, mas livra-nos destes males, assim como do despotismo ministerial, ou anarquia popular. Amem. (NEVES, 2003, p. 41) ${ }^{\mathrm{C}}$

Em ambos os casos, porém, salta aos olhos uma leitura messiânica da Constituição. E explicar a razão disso, realidade que como dito, se deu através do manejo da fé - porque fonte dos termos e da linguagem para a formulação de ideias naquela época e naquele

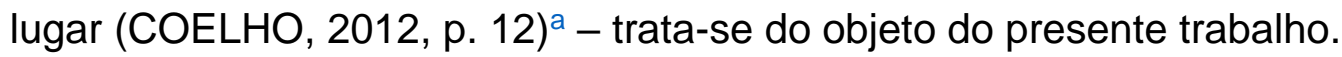

O que vale dizer, colhidos os resultados da pesquisa feita, alcançou-se como retorno ao problema proposto, a hipótese disso se dar por uma cultura social, tipicamente portuguesa, de contestação das dificuldades (LIMA, 2005, p. 237). ${ }^{a}$ Quer dizer, a ideia orientadora, portanto, será confirmar com base em bibliografia especializada, sermões de religiosos e semanários ou periódicos publicados - tudo isso quanto aos procedimentos metodológicos adotados, permitindo classificar a presente investigação como bibliográfica e documental - que apesar de toda perseguição pombalina perpetrada contra o mito milenarista-sebastianista, ou em outras palavras, ao culto de algo ou alguém que seria a solução de todas as mazelas e que instauraria um tempo de justiça, felicidade e paz em terras lusas. Tal modo de observar o mundo, sempre revivido em momentos de crise em 


\section{Passagens. Revista Internacional de História Política e Cultura Jurídica}

Rio de Janeiro: vol. 10, n⿳30 , setembro-dezembro, 2018, p. 399-413.

Portugal, como foram os períodos da Restauração, da invasão napoleônica, e mais especificamente, mediante as consequências deste último evento, o próprio vintismo. Também esteve presente no movimento constitucionalista luso-brasileiro do primeiro quartel do século XIX, e influenciou sob o manto da fé, os seus rumos.

\section{O mito do "desejado" ou o desenvolvimento sebástico em Portugal}

Para explicar o surgimento do que se tornou conhecido como sebastianismo, expressão de difícil definição, cunhada com o nome de um jovem rei português, $d$. Sebastião - também apelidado de "o Desejado" - que desapareceu em meio a uma batalha contra os mouros no ano de 1578 , no Marrocos. Outra alternativa não se afigura recomendável senão apontar para o torvelinho sentimental de expectativa e frustração que se formou em torno de seu reinado (HERMANN, 1998, p. 178). ${ }^{2}$

Assim é que herdeiro das decisões políticas de seu avô, d. João III, marcadas pela desonrosa perda de praças no norte da África, d. Sebastião, embora tenha assumido o trono de Portugal com a missão de retomar a empreitada - tida por destino lusitano - de construir e alargar um império de fé. ${ }^{1}$ Terminou, após a sua fragorosa derrota em Alcácer Quibir, adiando mais uma vez este projeto, que foi o responsável por atribuir a Portugal a posição de liderança na expansão ultramarina europeia. Bem como, dando ensejo a uma grave crise sucessória - já que não possuía filhos - que culminou no apossamento do assento régio por um estrangeiro - no caso, o castelhano Felipe II (HERMANN, 1998, p. 181). $\underline{\mathrm{b}}$

A partir daí, seguidos alguns casos de surgimento em meio a plebe, de falsos "Sebastiãos", como o da vila de Penamacor ou o outro da vila de Ericeira. ${ }^{2}$ Afinal, como o corpo do monarca nunca foi encontrado, uma forte crença popular, nesse meio de tempo, terminou surgindo em torno da possibilidade de que o mesmo pudesse estar perdido e que tão logo reencontrasse o caminho até Lisboa, trabalharia para recobrar a soberania portuguesa perdida. É fato que com o passar dos anos e frustradas pelo tempo as

\footnotetext{
${ }^{1}$ Quer dizer "terminar o projeto divino - converter o orbe em um só rebanho com um só pastor, em um só corpo com uma só cabeça (no caso, bipartida: espiritual e temporal)" (LIMA, 2005, p. 21) para a enfim instauração do quinto império, ou do Reino de Cristo, que segundo a leitura do livro de Daniel, do antigo testamento, seria precedido pelos impérios babilônico, persa, macedônio e romano.

2 Para mais informações sobre os falsos d. "Sebastiãos", ver a clássica obra "Les faux Don Sébastien" de Miguel D’Antas (1886). ${ }^{\text {a }}$
} 
esperanças de sua volta concreta, a história de d. Sebastião, pela proximidade de enredo, converteu-se no primeiro exemplar de uma construção cultural que se formou em terras lusas bem antes de seu nascimento e que continuaria manifestando-se por alguns séculos depois.

Quer dizer, há um certo consenso entre estudiosos do tema, de que o mito que encontra eco e se identifica material e inicialmente no contexto de vida de d. Sebastião, foi fomentado pelo trabalho de um sapateiro chamado Gonçalo Annes, popularmente conhecido como Bandarra, que com suas trovas muito populares, ${ }^{3}$ escritas entre os anos de 1510 e 1540, e que narravam a vinda de um rei instaurador da ordem (GOMES; CAMPOS; TEIXEIRA, 2014 p. 82). ${ }^{a}$ Deu o start para a produção de uma ideologia messiânico-milenarista ${ }^{4}$ em Portugal, que pouco a pouco, a partir de perdas e acréscimos aos textos do Bandarra, e, portanto, do surgimento de diferentes versões dos mesmos (SANTOS, T., 2009, p. 72), ${ }^{\text {a }}$ foi se distanciando da figura de d. Sebastião, para assumir, quando assim fosse o caso, outras manifestações.

Daí é que se $\mathrm{d}$. Sebastião representa a possibilidade de salvar Portugal do desvirtuamento de seu destino. Também é d. João IV, o restaurador, aquele que representa a libertação do país do jugo estrangeiro. E não bastasse a perseguição desempenhada pelo Marquês de Pombal, no reinado de d. José I - que mais do que ir ao encalço do sebastianismo em si, na verdade isso o fez por consequência do seu ódio aos jesuítas. ${ }^{5}$ Rompido o século XIX, e seguidas a invasão francesa e a fuga da família real para o Brasil, passa a "Santa Constituição", a ser daí a frente o novo depositório da esperança em meio aos reveses da pátria, como se verá adiante.

\section{Manifestações da crença taumatúrgica na Constituição antes da Independência do Brasil}

Vencido Napoleão no ano de 1815, tal fato gerou em Portugal enorme expectativa de que o rei fosse finalmente retornar ao país. No entanto, até o ano de 1820, d. João VI

\footnotetext{
3 Um poema de estrutura monotrófica que "andava em mãos de toda gente, lido, relido, decorado e discutido" (D'AZEVEDO, 1918, p. 87). ${ }^{\text {a }}$

${ }^{4} \mathrm{O}$ discurso messiânico, de inspiração judaica, pressupunha o aparecimento de um messias que libertaria 0 seu povo das humilhações sofridas, e quando associada ao milenarismo, era tida pela concepção de um rei que unificaria a cristandade e iniciaria um reino de júbilo, antes do juízo final (MAGALHÃES, 2009, p. 211). ${ }^{\text {a }}$ 5 Tidos por ele como os autores de tudo de funesto que havia se dado a Portugal, inclusive, esta, que era tida por uma infundada crença de um povo de ignorantes (MACEDO, J., 1810). ${ }^{a}$
} 


\section{Passagens. Revista Internacional de História Política e Cultura Jurídica}

Rio de Janeiro: vol. 10, n⿳30, setembro-dezembro, 2018, p. 399-413.

não demonstrava qualquer interesse em proceder dessa maneira. Fato que consolidou um pesado ressentimento ${ }^{6}$ entre aqueles que lá residiam (VILLALTA, 2016, p. 184). ${ }^{a}$ E que tanto fez com que alguns setores da nobreza clamassem pela superação da situação de decadência na qual se encontrava o reino ${ }^{7}$ - o que passava, acreditavam, pelo retorno imediato do rei e pela convocação das cortes tradicionais baseadas na representação consultiva dos segmentos da Igreja, da nobreza e do povo. Como também motivou os liberais a defenderem o mesmo objetivo junto da necessidade de regresso do monarca, só que em divergência, pleiteavam noutro giro a instalação de cortes formada pela reunião de deputados eleitos, que em caráter extraordinário e inédito realizariam a função constituinte.

Bem encaminhada a proposta do segundo grupo, inicialmente com um levante militar em agosto de 1820, que logo se dirigiu, após a adesão de Lisboa e de outras províncias em Portugal, a posse em 26 de janeiro de 1821, dos primeiros 100 parlamentares nas cortes. $^{8}$ Chama a atenção neste ínterim, a fala de um padre de Coimbra que se via na obrigação de explicar o que é e com que Direito a nação iria formar uma constituição, porque muitos, segundo ele, não tinham noção nenhuma ou não as tinham exatas acerca disso (VIEIRA, 1992, p. 231). ${ }^{a}$

$\mathrm{Na}$ explanação, em que o clérigo destacava que se o povo percebe que o soberano não exerce os direitos como deve e segundo o fim para que lhes foram dados. E se exatamente por ser deste modo, corre o risco de submergir no estado de que quisera fugir, quando celebrou no passado um pacto social com o monarca. É evidente que este mesmo povo deve reassumir s direitos que cedera ao soberano para tomar novas cautelas, o que

\footnotetext{
6 "desde 1808 difundira-se em Portugal o sentimento de ser colônia de uma colônia: invasões napoleônicas em 1808 e 1809, dominação inglesa de 1808 a 1815 e a transferência da corte para o Rio de Janeiro revelavam a perda de autonomia do reino. A presença da corte no Rio de Janeiro simbolizava a inversão dos papeis entre as partes da monarquia. Essa presença e o crescente- movimento comercial nos portos da América evidenciavam o papel secundário da economia do reino português, agora relegado à sua própria produção" (BERBEL, 2006, p. 184). ${ }^{2}$

${ }^{7}$ A realidade na qual se achava Portugal naquele momento histórico, de 1820, era uma onde o mesmo "estava aniquilLado no meio das mais nações, que d'elle não faziam caso algum; o território da pátria estava retalhado por hespanhoes, francezes e inglezes; a nossa bandeira era continuamente insultada e enxovalhada por amigos e inimigos, sem termos força para desafrontar, e as côrtes estrangeiras tratavam-nos como se fossemos um povo despresível. E para recuperamos o prestígio no exterior e curarmos as grandes feridas que sangravam dentro, nomeava-se presidente da regência o fanático patriarcha de Lisboa. É que d. João VI só pensava em aniquillar todos os pedreiros livres e jacobinos, como d. João III os herejes e protestantes. Elle não se importava com o levantar a pátria abatida e humilhada; mas como o manter seus augustos direitos e interesses" (D'ARRIAGA, 1886, p. 574-575). ${ }^{\text {a }}$

8 Isso porque, como se sabe, os deputados das províncias de ultramar só se apresentaram ás cortes, passado um bom tempo, já que antes de se proceder as eleições, se procedeu a uma discussão das regras que para elegê-los seriam seguidas.
} 


\section{Passagens. Revista Internacional de História Política e Cultura Jurídica}

Rio de Janeiro: vol. 10, n⿳30 , setembro-dezembro, 2018, p. 399-413.

ele chama de constituição. E que para isso, necessária será a concorrência de deputados animados não só de valores, mas também de religião. Qualidades que associadas em seu pronunciamento, denotam cristalinamente a lógica que orientou os revolucionários vintistas e seus adeptos, qual seja: a de que longe de negar espaço a certeza tradicional da fé, na verdade quis casar a nova ideologia que propagandeava - o liberalismo - com um referencial simbólico de unidade e coesão nacional - o catolicismo - de modo a que esse pudesse apadrinhar a chegada daquele (SARDICA, 2002, p. 132). ${ }^{\text {a }}$

Quer dizer, a ideia dos insurgentes era revestir o novo discurso político com uma roupagem de fórmulas, imagens e conceitos, que fosse do conhecimento de todos, mesmo aqueles que não fossem letrados, para alcançar o mais longínquo rincão e atingir a mais ampla aceitação popular. ${ }^{9}$ Daí, aliás, a abundância, entre os anos de 1820 e 1823, de referências elogiosas, tais como, quanto à constituição: "o sagrado código"; quanto as cortes: "o santuário da lei"; e quanto aos deputados eleitos: os "apóstolos da liberdade". Isso sem falar na proliferação de catecismos, de orações e credos patrióticos. E mais até esclarecedor, no fato de que as principais manifestações cívicas tinham normalmente, a igreja como cenário, a missa como ritual, o Te-Deum como hino oficial, e o pároco como o oficiante.

É o caso, por exemplo, do sermão "gratulatório", de autoria do padre Manoel Rodrigues Jardim, ${ }^{10}$ que recitado na Igreja de Nossa Senhora do Carmo de Villa rica - atual Ouro Preto - na presença do Governador, do Capitão General, da Câmara, do Clero, da Nobreza e do Povo do lugar. Após solene juramento prestado por todos estes às bases da constituição. Fazia menção as preciosas vantagens e bens singulares de uma constituição liberal - no caso, o fim a que ela, o maior bem concedido pelos céus, colocaria às situações como a do ouro do poderoso que arranca dos tribunais sentenças de iniquidade; e a da absorção do Estado pela avidez dos hipócritas, que rojando sua ignorância no palácio, estudavam meios para extorquirem graças do príncipe (JARDIM, 1821, p. 09). ${ }^{\text {a }}$

\footnotetext{
9 "A nova classe dominante pretendia, assim, diminuir a influência (tradicional) da instituição religiosa nas comunidades e transformá-la num mero instrumento do Estado. Nesse ensejo, os líderes políticos reassumiram as teses regalistas e, a essa luz, procuraram utilizar o aparelho eclesiástico na difusão das ideias constitucionais" (NETO, 1993, p. 265). ${ }^{\text {a }}$

${ }_{10}$ Algo que se dava pois "o cristianismo era o quadro preponderante e frequentemente o único que permitia, quando necessário, consagrar ou solenizar um acontecimento" sobretudo, em Portugal (TACKETT, 1986, p. 25). ${ }^{\mathrm{a}}$
} 


\section{Passagens. Revista Internacional de História Política e Cultura Jurídica}

Rio de Janeiro: vol. 10, n⿳30 , setembro-dezembro, 2018, p. 399-413.

Bem como, da carta pastoral do Arcebispo da Bahia e primeiro presidente das cortes - d. Vicente de Castro - que determinava aos párocos que estes transmitissem à seus fregueses, junto do temor à deus, também o respeito e obediência às legítimas autoridades terrenas, e a confiança e o amor ao novo sistema de governo e a constituição portuguesa que se redigia, - "arma como de hum affiado machado para extirpar criminosos abusos, levados ao último excesso e, que faziõ a Naçaõ verdadeiramente desgraçada" (CASTRO, 1821, p. 01-07). ${ }^{a}$ E ainda, das súplicas contidas na Ladainha Constitucional, para que o texto magno se compadece-se dos portugueses e assim os livrasse especialmente: do poder judiciário arbitrário; da falta de responsabilidade dos ministros; da falta de crédito público; da introdução dos cereais estrangeiros por contrabando; dos monopólios em azeite; do luxo asnático; da guerra civil; da desunião do Brasil; desse perguntar, porque não se cumprem as ordens das cortes?; da demora da reforma da universidade; do ódio aos periódicos; e ainda, dentre outros, da falta de religião. Sendo tudo isso pedido, em meio a tantos, em nome do sossego milagroso, e com que sem efusão de sangue, se fez a regeneração da pátria. Para que, por fim, os que mandam e são mandados tenham conhecimento dos limites de seus direitos, ou para que fossem abolidos todos os vestígios do feudalismo (LADAINHA..., 1822, p. 01-07). ${ }^{\text {a }}$

Tais manifestações, embora transmitam a ideia de constituição como uma entidade mítica, de que irradiam sabedoria, felicidade e prosperidade gerais (CAETANO, 1987, p. 482). ${ }^{a}$ Ou em outros termos, sejam verdadeiros exemplares de profissão de fé política em um nível à beira do taumatúrgico (VIEIRA, 1992, p. 21; ${ }^{\text {b }}$ CANOTILHO, 1993, p. 149; 157)a - característica que ostentam por conta do próprio desenvolvimento de Portugal, que como já destacado, sempre quando diante da decadência projetava de maneira inconsciente o regresso de uma forma mítica de sentir e pensar o complexo sebastianista. ${ }^{11}$ Não foram, porém, suficientes para manter unidos em esperança, ao menos não quanto ao mesmo destino que se buscava alcançar, aqueles que defendiam os interesses do Brasil. Afinal, o que se trata do foco do ponto adiante, porque a crise era vivenciada de modo diferente em Portugal e no Brasil, a diversidade de projetos para a resolução da mesma, terminou por

\footnotetext{
11 O que vale destacar, não há conflito em ver uma perspectiva sebastianista da constituição ser divulgada por intermédio da religião católica, que já contem em si seu próprio messias. Afinal, ainda que o d. Sebastião histórico tenha se convertido em d. Sebastião mítico, verdadeiro Cristo nacional. O Sebastianismo ou a ideia que o mesmo trazia consigo, de esperança em meio a períodos de decadência, jamais atingiu em Portugal a categoria de Deus.
} 
dividir os deputados de ambos os países na assembleia ${ }^{12} \mathrm{e}$ isso foi determinante para a independência do Brasil (BERBEL, 2006, p. 183). ${ }^{b}$ Que agora separado, suscitaria quando da constituinte de 1823, seu próprio sebastianismo, valendo-se também para tanto da instrumentalização da fé.

\section{A efemeridade do sebastianismo constitucional no império dos trópicos}

No início de 1821, quando as cortes já se encontravam instaladas em Lisboa, inaugurou-se entre os deputados portugueses um intenso debate sobre a representação do Brasil na assembleia. Decidindo-se no curso deste, primeiro por se esperar o posicionamento das então capitanias quanto a adesão ao movimento constitucional. $E$ segundo, logo após aquele, por convocar enfim a eleição dos parlamentares brasílicos, sem, porém, definir um calendário comum para tanto. O que vale realçar, resultou no fato dos deputados brasileiros chegarem em Lisboa somente entre o fim de agosto de 1821 e o mês de julho de 1822. E ainda, na situação de que províncias como Minas Gerais e Rio Grande do Norte, sequer chegaram a ter um representante (SILVA, 1988, p. 91). ${ }^{\text {a }}$

Apesar de assim ter sido, é certo que sem sentimento de revanche, os mais diversos esforços foram envidados pela deputação brasiliense - na medida em que foram se apresentando - no sentido de manter a integridade do Reino. Até porque, pelos debates, fica nítido que faltava a eles unidade na maior parte das pautas, já que como o Brasil era e permanece imenso em território, o mesmo, na figura de seus representantes, se dividia e se contradizia muitas vezes, dado aos interesses distintos que nutriam as províncias.

No entanto, considerando a inflexão das cortes no tocante aos poucos assuntos que eram consensuais para a maior parte dos portugueses americanos. Sobretudo quando no segundo semestre de 1821 as mesmas decidiram criar juntas provisórias de governo nas provinciais, com quadros de livre nomeação e exoneração por decisão da assembleia; exigir o retorno urgente do príncipe regente d. Pedro, para Portugal; e por último, abolir os tribunais superiores de justiça que haviam sido instalados por d. João VI, no Rio de Janeiro (NEVES, 2003, p. 283). ${ }^{d}$ Todos estes feitos tomaram ares de grande choque entre a

\footnotetext{
12 Isso porque, "se polarizavam cada vez mais as divergências entre os portugueses Integristas, partidários do país único, com um só parlamento, uma só nação e submetidos ao mesmo Rei; e os brasileiros Unionistas, partidários da integração sob a manutenção de dois reinos, dois territórios autônomos, com instituições próprias, mas sob a autoridade do mesmo monarca" Cf. Macêdo, T. (2015, p. 59). .
} 
população brasílica, a ponto, inclusive, de se ouvir pelas ruas que se "a constituição é fazerem-nos mal, leve ao diabo tal coisa" (NEVES, 2003, p. 291). ${ }^{\circledR}$

Cenário que quando erigido, não por outro motivo é porque vemos no púlpito das Igrejas, local por excelência que naquele momento servia de polo circulante das ideias (DURAN, 2010, p. 110-111), a uma perspectiva mais crítica. Como é o caso "do Prócer da Independência" (TITTON, 1972, p. 590) ${ }^{\mathrm{a}}$ - ou Frei Francisco de Santa Teresa de Jesus Sampaio - que na dedicatória ao senado do seu discurso do dia 15 de setembro de 1821, dizia que desde 26 de fevereiro daquele ano havia começado a anunciar os seus sentimentos mais verdadeiros sobre a vantagem da constituição vintista (TITTON, 1972, p. 594). ${ }^{\text {b }}$ Mas no dia 25 de maio de 1822, logo após uma revolta que se instaurou na Bahia e que foi sufocada pesadamente por forças militares portuguesas se manifestou afirmando que:

Homens pérfidos nos havião prometido que seriamos livres, como as Nações polidas, logo que nos jurássemos a Constituição; mas eles tinhão na ideia reduzirnos á hum estado peior do que o da antiga escravidão: para nos conservarem oprimidos nos cercarão com assassinos debaixo de cujas armas nossos Pais cahirão mortos só pelo crime de sua sinceridade, e de sua boa fé. Eis aqui em Rezumo a história da Constituição na Bahia: não se procurem pretextos, não se renovom promessas, não se suponha que a nossa confiança tornará a renascer, a trahição está manifesta, e já á vista das Nações da Europa. Todas conhecem igualmente com nosco que nunca foi da intenção dos nossos pertendidos Regeneradores conservar as inauferíveis atribuições do Reino do Brasil porque he sobre os pedestaes de nossa agricultura escravizada, de nosso commercio entorpecido, da nossa indústria paralizada que os novos Arcontes pertendião elevar huma monarquia inteiramente desgraçada, depois que eles se ajuntarão para destruírem o germen dos seus males. Dezenganemo-nos por tanto que a nossa felicidade só pode ser obra das nossas mãos debaixo das vistas do grande Arbitro dos Impérios (PAIO, 1822, p. 20). ${ }^{\text {a }}$

E porque vemos também, periódicos e folhetos que se antes, na fase inicial do movimento de 1820, tinham por preocupação apenas cuidar da oposição: governo despótico versus governo constitucional. Posteriormente, quando do começo de 1822, a maioria daqueles produzidos no Brasil, passaram simplesmente a adotar uma postura mais fraca (SILVA, 1988, p. 16) ${ }^{\mathrm{b}}$ quanto à formação de um Império independente e à elaboração de uma constituição própria. ${ }^{13}$ Como é o caso do Revérbero Constitucional Fluminense,

\footnotetext{
13 "se inicialmente, os jornais e folhetos que circularam na América permitiram o estabelecimento de um diálogo entre as elites brasileira e portuguesa, que não colocou em questão a integridade do Reino Unido, os acontecimentos em Portugal no final de 1821, ligados às medidas das Cortes portuguesas em relação ao Brasil, trouxeram uma mudança nas palavras e nas ideias e conduziram a um novo ideário, relacionados a algumas propostas de separatismo" (NEVES, 1999, p. 09). ${ }^{\text {a }}$
} 


\section{Passagens. Revista Internacional de História Política e Cultura Jurídica}

Rio de Janeiro: vol. 10, n⿳30, setembro-dezembro, 2018, p. 399-413.

que em seu número 25 , datado de fins de abril daquele ano corrente, instava d. Pedro a atuar neste sentido, com tons de piedade enfática, declarando:

Sim, Príncipe, rasguemos o véo dos Mystérios, rompa-se a nuvem, que encobre o Sol, que deve raiar na Esphéra do Brasil. Eleva, eleva o Templo da Liberdade Brasileira; forme-se nelle o Livro da Lei, que nos deve reger, e sobre as Bases já por nós juradas, em grande pompa seja conduzido e depositado sobre as Aras do Deos de nossos Pais; ahi, diante do Altíssimo, que te há de ouvir, e punir se fores trahidor, jura defende-la, e guarda-la à conta do teu próprio sangue; jura identificarte com ella; o Deos dos Christãos, a Constituição Brasílica, e Pedro, eis os nossos votos, eis os votos de todos os bons brasileiros [...] Oh dia de Glória! Quanto és bello, até mesmo lobrigado por entre as nevos do futuro! [...] Príncipe, só assim baquearão de huma vez os cem Dragóes, que rugem, e procurarão devorar-nos [...] Não despréses a gloria de ser o fundador de hum novo Império (REVÉRBERO..., 1822 , p. 303). ${ }^{\text {a }}$

Colocações que daí em diante, com a convocação de uma assembleia constituinte por d. Pedro, em junho de 1822, ${ }^{14}$ e a consumação oficial da independência com a sua proclamação no famigerado 07 de setembro, ganham gradativamente corpo. E fizeram deslocar as críticas dirigidas às cortes para Portugal; converter os portugueses em

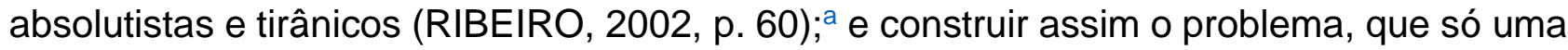
constituição novamente sebastianista, no que se refere agora as expectativas do Brasil, poderia vir a dirimir.

É o que vemos no Regulador Brasileiro, especificamente no seu nำ18, quando este coloca que se o interesse do Brasil é o de escapar da alcunha de escravo, a alternativa não poderia ser outra senão confiar no jovem imperador, que tal como o seu congênere romano, de nome Constantino, faria da constituição o lábaro ou estandarte do primeiro império do sul do novo mundo, ${ }^{15}$ para espantar as nações já estabelecidas, e dentre elas, a naçãomãe, ou Portugal (REGULADOR... 1822, p. 268). ${ }^{2}$

Como igualmente trata-se do que observamos no sermão de aclamação de d. Pedro como primeiro imperador do Brasil, pronunciado pelo outrora revoltoso, ${ }^{16}$ Frei Joaquim do Amor Divino Rabelo, conhecido popularmente como Frei Caneca. Que na matriz do Corpo Santo, na cidade de Recife, em 08 de dezembro de 1822, logo após destacar que o Brasil esteve por três séculos submetido a um tirocínio bárbaro e cruel, e que os membros do

\footnotetext{
${ }^{14}$ Embora a ideia inicial que dos escritos da época deixam transparecer fosse mais salvar o constitucionalismo português de seu maior inimigo, as cortes, e proporcionar a autonomia do Brasil, do que propriamente produzir o texto de um país independente (RIBEIRO, 2002, p. 52). ${ }^{\mathrm{b}}$

${ }^{15}$ A referência é ao famoso estandarte romano no qual o imperador Constantino fez colocar o monograma do nome de Cristo em grego, e a isso atribuía suas vitórias em campanhas militares.

${ }^{16}$ Porque insurgente ativo na Revolução Pernambucana de 1817 ou Revolução dos Padres.
} 
congresso de Lisboa queriam com o rasgo de suas penas manter o país nesta situação

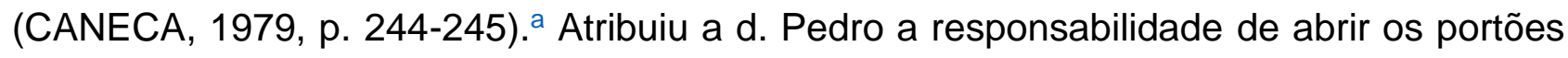
do Império Constitucional. Isto é, de dar início ao processo de instalação no Brasil, de uma "concepção de inteligência acima dos mortais" (CANECA, 1979, p. 247), ${ }^{\mathrm{b}}$ cuja missão era derrotar o despotismo - causa da ruina das ciências, das artes, dos costumes, da razão e da liberdade. E permitir o gênio brasileiro apresentar seus prodígios em todos os campos, sob a sempiterna proteção da excelsa Senhora, a conceição intemerata ${ }^{17}$ da formosa roseira de Jericó (CANECA, 1979, p. 248-249). ${ }^{\circ}$

Prelúdios de euforia, cada qual, entretanto, que rapidamente irão se dissipar em meio a um conjunto de prisões, deportações, espionagem policial e restrições à liberdade de imprensa que logo desembocaria no fechamento da constituinte (SODRÉ, 1999, p. 61; 76). ${ }^{\text {a }}$ O que regressando à época anterior a 1820, faria da constituição não mais a herança de um sebastianismo, cuja meta era deixar para trás o velho regime e suas consequências deletérias, mas sim um ato de clemência do rei perante o espírito de um tempo novo (CANOTILHO, 1993, p. 154), ${ }^{\text {b }}$ ou a adesão à continuidade adaptada, ${ }^{18}$ em detrimento da ruptura (HESPANHA, 2004, p. 125). ${ }^{\text {a }}$

\section{Conclusão}

O presente trabalho teve por objetivo apresentar algumas considerações a respeito do uso da fé para a propagação de uma ideia sebastianista de constituição em terras lusobrasileiras. Para tanto, em um primeiro momento, focou na explicação histórica do surgimento do mito do sebastianismo, preocupando-se por situá-lo como um exemplar messiânico-milenarista, que ao longo das situações de dificuldade enfrentadas por Portugal no curso do tempo, e ainda, junto às adaptações dos textos do Bandarra, aos poucos distanciou-se de d. Sebastião para assumir outras vertentes, até que se alcançasse a Revolução do Porto e a constituição.

\footnotetext{
17 Menção à Virgem Maria sob o título de Nossa Senhora da Conceição, pois como somente em novembro de 1822, a câmara de Recife recebeu o comunicado da câmara do Rio de Janeiro para que preparassem a aclamação do "sereníssimo senhor d. Pedro" como imperador do Brasil. Acordou-se, portanto, que isso se faria no dia 08 de dezembro, por ser este dia dedicado a padroeira do Reino de Portugal, cuja festa era bastante celebrada (SANTOS, L., 2011, p. 23). ${ }^{\text {a }}$

${ }_{18} \mathrm{O}$ que se materializará no chamado cartismo, que consiste numa relegitimação do poder constituinte monárquico.
} 


\section{Passagens. Revista Internacional de História Política e Cultura Jurídica}

Rio de Janeiro: vol. 10, n⿳3 , setembro-dezembro, 2018, p. 399-413.

Bem como, logo em seguida, cuidou de apontar as manifestações de fé na constituição, no período pré-independência do Brasil. Mostrando como a religião, seja por meio dos seus interlocutores, seja por intermédio das figuras de linguagem, foi nesta etapa essencial para o sucesso do primeiro contato entre a população e o texto constitucional cuja necessidade e o papel pouco se conhecia, mas que se instava a crer que resolveria tudo de ruim pelo qual passava o Império. O que também foi o tom no momento pósindependência e da constituinte de 1823, até, porém, que frente ao fator real de poder preponderante, ou d. Pedro I, a esperança na transição do velho para um novo regime, terminou por ceder lugar a um continuismo meramente adaptado.

\section{Referências}

BERBEL, Márcia. Os apelos nacionais das cortes constituintes de Lisboa. In: MALERBA, Jurandir (Org.). A independência brasileira: novas dimensões. Rio de Janeiro: FGV, 2006. p. $181-208$., b $^{a}$

BRASIL. Congresso. Câmara dos Deputados. Centro de Documentação e Informação. $O$ clero no parlamento brasileiro. Rio de Janeiro: Fundação Casa de Rui Barbosa, 1978. ${ }^{a}$

CAETANO, Marcelo. Direito constitucional. Rio de Janeiro: Forense, 1987. ${ }^{a}$

CANECA, Frei Joaquim do Amor Divino. Obras políticas e litterárias de frei Joaquim do Amor Divino Caneca. Organização de Antônio Joaquim de Melo. Recife: Assembleia Legislativa de Pernambuco, 1979. a, b, c

CANOTILHO, José Joaquim Gomes. Direito constitucional. Coimbra: Almedina, 1993. a, b

CASTRO, Dom Frei Vicente da Soledade e. Pastoral do arcebispo da Bahia sobre a instrucção christã e constitucional dos seus diocesanos. Lisboa: Typographia de António Rodrigues Galhardo, 1821. ${ }^{a}$

COELHO, Luiz Filipe Alves Guimarães. Os reinos de Daniel: profecia e política em Portugal e na Inglaterra do século XVII. 2012. Dissertação (Mestrado em História)-Universidade Federal Fluminense, Niterói, 2012. ${ }^{a}$

D’ANTAS, Miguel. Les faux D. Sébastien: études sur l'histoire du Portugal. Paris: Chez Auguste Durand, 1886. ${ }^{a}$

D'ARRIAGA, José. História da Revolução Portuguesa de 1820. Porto: Livraria Portuguesa Lopes \& Cia Editora, 1886. v. 1. ${ }^{a}$

D’AZEVEDO, João Lúcio. A evolução do sebastianismo. Lisboa: Livraria Clássica, 1918. ${ }^{a}$ 
DURAN, Maria Renata da Cruz. Ecos do púlpito: oratória sagrada no tempo de d. João VI. São Paulo: Unesp, 2010. ${ }^{\text {a }}$

GOMES, Álvaro Cardoso; CAMPOS, Alzira Lobo de Arruda; TEIXEIRA, Eliane de Alcântara. O sebastianismo: uma reflexão histórica e literária do mito. Revista Lumen et Virtus, v. 5, n. 10 , p. $72-94,2014 .^{a}$

HERMANN, Jacqueline. No reino do desejado: a construção do sebastianismo em Portugal. São Paulo: Companhia das Letras, 1998. ${ }^{\mathrm{a}, \underline{b}}$

HESPANHA, António Manuel. Guiando a mão invisível: direitos, estado e lei no liberalismo monárquico português. Coimbra: Almedina, 2004. ${ }^{a}$

JARDIM, Padre Manoel Rodrigues. Oração Gratulatória que depois do solemne juramento prestado a's bases da constituição... Rio de Janeiro: Nova Officina Typographica, 1821. ${ }^{a}$

LADAINHA constitucional, segundo o espírito da Constituição. Lisboa: João Nunes Esteves, 1822. ${ }^{a}$

LIMA, Luis Filipe Silvério. O império dos sonhos: narrativas proféticas, sebastianismo e messianismo brigantine. 2005. Tese (Doutorado em História Social)-Universidade de São Paulo, São Paulo, 2005.

MACEDO, José Agostinho de. Os sebastianistas. Lisboa: Impressão Régia, 1810. ${ }^{a}$

MACÊDO, Tomás Brandão de. Perspectivas políticas e jurídicas acerca do Brasil nas cortes constituintes de 1821-1822. 2015. Dissertação (Mestrado em Direito)-Faculdade de Direito, Universidade de Coimbra, Coimbra, 2015. ${ }^{a}$

MAGALHÃES, Leandro Henrique. A tradição messiânica portuguesa e a constituição do quinto império. Tuiuti: Ciência e Cultura, Curitiba, n. 41, p. 209-220, jan-jun. 2009. ${ }^{a}$

NETO, Vitor. O Estado e a Igreja. In: MATTOSO, José (Org.). História de Portugal. Lisboa: Círculo de Leitores, 1993. v. 5, p. 265-284. ${ }^{a}$

NEVES, Lúcia Maria Bastos Pereira das. A "guerra de penas": os impressos politicos e a independência do Brasil. Tempo, Niterói, n. 08, p. 1-17, 1999. ${ }^{2}$

NEVES, Lúcia Maria Bastos Pereira das. Corcundas e constitucionais: a cultura jurídica da independência (1820-1822). Rio de Janeiro: Revan/FAPERJ, 2003. a, b, c, d, e

PAIO, Frei Francisco de S. Oração fúnebre pelos mortos... Rio de Janeiro: Imprensa Nacional, 1822. ${ }^{a}$

REGULADOR BRASILEIRO. Rio de Janeiro: Imprensa Nacional, 1822. ${ }^{a}$

REVÉRBERO CONSTITUCIONAL FLUMINENSE. Rio de Janeiro: Typographia de Mor Garcez, 1822. ${ }^{a}$ 
RIBEIRO, Gladys Sabina. A Liberdade em construção. Rio de Janeiro: RelumeDumará/FAPERJ, 2002.a, b

SANTOS, Lídia Rafaela Nascimento dos. Das festas aos botequins: organização e controle dos divertimentos no Recife (1822-1850). 2011. Dissertação (Mestrado em História)-Universidade Federal de Pernambuco, Recife, 2011. ${ }^{\text {a }}$

SANTOS, Tania Lima dos. A (re) escritura mítica do sebastianismo no Romance d'A Pedra do reino, de Ariano Suassuna. 2009. Tese (Doutorado em Letras)-Universidade Federal da Paraíba, João Pessoa, 2009. ${ }^{a}$

SARDICA, José Miguel. O vintismo perante a Igreja e o catolicismo. Penélope, Lisboa, $\mathrm{n}$. 27 , p. $127-160,2002 .^{a}$

SILVA, Maria Beatriz Nizza da. Movimento constitucional e separatismo no Brasil, 18211823. Lisboa: Livros Horizonte, 1988. a, b

SODRÉ, Nelson Werneck. História da imprensa no Brasil. Rio de Janeiro: Mauad, 1999. a

TACKETT, Timothy. La Révolution, l'eglise, la France, le serment de 1791. Paris: Les Éditions du Cerf, 1986. ${ }^{\text {a }}$

TITTON, Gentil Avelino. Um prócer da independência: Frei Sampaio. Revista Eclesiástica Brasileira, Petrópolis, v. 32, n. 126, p. 590-611, 1972.a, b

VIEIRA, Benedita Duque. O problema politico português no tempo das primeiras cortes liberais. Lisboa: Sá de Costa, 1992.a, b

VILLALTA, Luiz Carlos. O Brasil e a crise do Antigo Regime português (1788-1822). Rio de Janeiro: FGV, 2016. ${ }^{a}$ 